\title{
Anticuerpos monoclonales para el manejo del asma: de las guías a la medicina personalizada
}

\section{Monoclonal antibodies for asthma management: from guides to personalized medicine}

\author{
Diana L. Silva E. MD. ${ }^{(1,2)}$; LUIS FeRnando RamíREZ Z., MD. ${ }^{(1,2)}$; \\ CARLos DANIEL SERRANO R., MD. ${ }^{(1,2)}$
}

\begin{abstract}
Resumen
El asma es una enfermedad multifactorial y compleja, con diferentes grados de riesgo y gravedad, así como de respuesta al tratamiento. La mayoría de veces, los medicamentos disponibles son efectivos en el asma grave; sin embargo, existe un porcentaje de pacientes que no responde al tratamiento que sugieren las guías. En los últimos años ha venido investigándose el papel de moléculas inflamatorias que contribuyen a la fisiopatología del asma, y muchas de ellas se han considerado posibles dianas en el manejo del asma grave. Como consecuencia de esto, se han desarrollado algunos anticuerpos monoclonales que han probado su efectividad en el tratamiento de la enfermedad. El estudio de estas nuevas terapias ha permitido a su vez identificar nuevas vías inflamatorias específicas. Este artículo pretende dar una visión crítica de las guías actuales para el manejo del asma grave, así como discutir su tratamiento actual y futuro, a la luz de las nuevas evidencias moleculares. Mediante una caracterización adecuada, se podrán reconocer diferentes fenotipos que a su vez están asociados con un determinado biomarcador, el cuál deberá utilizarse para seleccionar el tratamiento que pueda ofrecer la mayor efectividad en estos pacientes. De esta forma, el tratamiento estará dirigiéndose hacia una medicina personalizada.
\end{abstract}

Palabras clave: asma grave, guías de manejo, anticuerpos monoclonales, fenotipos, endotipos, interleucinas 4, 5, 13, linfoproteína tímica estromal, biomarcadores.

\begin{abstract}
Asthma is a multifactorial and complex desease, with different degrees of risks and severity, as well as the response to treatment. Medications currently available are mostly effective in severe asthma; nonetheless, there is a percentage of patients that have no response to the treatment that guidelines suggest in their recommendations. In the last years there has been researches in inflammatory molecules that contribute in asthma physiopathology and a lot of them have been considered to be possible targets in the management of severe asthma.

As a consequence of this, a few monoclonal antibodies have been developed evidencing their effectiveness in the treatment of the disease. The study of these new therapies has allowed the identification of specific inflammatory pathways. This article pretends to offer a critical perspective of the current guidelines for the management of severe asthma, as well to discuss current treatments and the future in spot of the new molecular evidences. Through an adequate characterization, different phenotypes will be recognised and associated with a determinate biomarker, and should be used to select the treatment that can offer the highest effectiveness in this patients. In this way, the treatment will be directed to a personalized medicine.
\end{abstract}

Keywords: severe asthma, monoclonal antibodies, treatment, phenotype, endotype, IL-4, IL-13, TSLP, IL-5, biomarker.
${ }^{(1)}$ Unidad de Alergia. Fundación Valle del Lili. Cali, Colombia.

${ }^{(2)}$ Facultad de Ciencias de la Salud. Universidad Icesi. Cali, Colombia.

Correspondencia: Carlos Daniel Serrano, correo electrónico: cdserranoreyes@gmail.com Recibido: 30/10/16. Aceptado: 15/11/16. 


\section{Introducción}

El asma es una enfermedad heterogénea caracterizada por una inflamación crónica de la vía aérea. Las guías GINA indican que el control de la inflamación es clave para el manejo y por consiguiente es la prioridad en el tratamiento. El asma grave representa buena parte del gasto sanitario, con una repercusión significativa en la calidad de vida de los pacientes, de ahí que la identificación y el tratamiento correcto pueden ayudar al control de las exacerbaciones y del proceso inflamatorio, mejorando así el impacto personal, social y económico de la enfermedad (1).

En la fisiopatología del asma intervienen múltiples procesos mediados por diversas citocinas y células que hacen que la inflamación se perpetúe en el tiempo y, por ende, el manejo se ha direccionado hacia el control de ésta mediante el uso de corticoides, los cuales han significado un cambio dramático en el control de la enfermedad. Sin embargo, estos fármacos actúan de una forma inespecífica sobre diversos mediadores. Por esto, es muy importante destacar que el desarrollo de nuevos anticuerpos monoclonales podría traer consigo un cambio significativo en la manera de tratar la enfermedad, reforzándose así la idea esencial de una medicina personalizada.

En 1984, los investigadores Jerne, Köhler y Milstein, recibieron el premio Nobel de Medicina por su trabajo de fusión de células plasmáticas con las de mieloma múltiple, lo que permitía la generación de anticuerpos específicos con la información genética adecuada, pero a una velocidad elevada. En los años subsiguientes se comenzaron a publicar estudios que utilizaron inmunoglobulinas sintetizadas a partir de esta nueva tecnología, con moléculas diana específicas, como la endotoxina de las bacterias gramnegativas en la sepsis, demostrando un beneficio inicial. Posteriormente, el concepto de la medicina personalizada comenzó a tomar forma y es por ello que, en los últimos años, la investigación biomédica se ha centrado en profundizar en los mecanismos moleculares que subyacen a diversas patologías, así como en la producción de nuevos fármacos que actúen en puntos cruciales de cascadas inmunológicas específicas. De esta forma, hoy en día los anticuerpos monoclonales constituyen una alternativa terapéutica efectiva y segura en muchas enfermedades crónicas como la artritis reumatoide, el cáncer y el asma, y se vislumbran como una opción esperanzadora en muchas otras. El reto ahora consiste en no perderse en la gran variedad de estudios clínicos que se pueden encontrar en la literatura, así como en lograr conectar un paciente en particular con el manejo apropiado basado en la evidencia.

\section{Visión crítica de las guías y del tratamiento actual}

\section{¿Es adecuado y suficiente el manejo basado en el control ylo la gravedad?}

Los grandes estudios sobre asma grave han expandido el conocimiento en cuanto a las diversas características de la enfermedad. La gravedad se define como el requerimiento de corticoides sistémicos más de dos veces en año, la necesidad de al menos una hospitalización, el ingreso previo a una unidad de cuidado intensivo, la necesidad de ventilación mecánica en el año previo, la alteración de la función pulmonar determinada por un volumen espiratorio forzado en el primer segundo $\left(\mathrm{FEV}_{1}\right)$ menor al $80 \%$ del predicho en presencia de una capacidad vital forzada (CVF) inferior a los límites normales después de la administración de broncodilatador, o el uso de altas dosis de corticoides inhalados y agonistas beta-2 de acción prolongada sin lograr el control de los síntomas (2). De hecho, se estima que un $50 \%$ de los pacientes no están bien controlados a pesar de recibir tratamiento óptimo, y que un 5-10\% no responden al tratamiento. Además, recibir dosis altas de corticoides inhalados o sistémicos conlleva la posibilidad de presentar efectos adversos inherentes, lo cual implica una afectación de la calidad de vida adicional por la suma de otras enfermedades secundarias (3).

Las guías GINA se basan en la evidencia y muchas de las decisiones terapéuticas que proponen derivan de estudios que cumplen con todos los criterios de validez científica. Sin embargo, es posible que los pacientes seleccionados, quienes cumplen con rigor ciertas características para la inclusión, no sean el fiel reflejo del paciente que el clínico aborda rutinariamente. Las guías sugieren pautas de manejo 
según la gravedad y el control, la dinámica de los síntomas y la función pulmonar, pero éstas van dirigidas a la población total de pacientes con asma (1). En este sentido, siempre habrá un porcentaje de pacientes que, o bien reciben un tratamiento sub óptimo (incluso con el uso de medicamentos de primera línea), o que permanecen sin respuesta a pesar de estar encasillados en el escalón de mayor gravedad. Finalmente, las guías no se basan en las características de la inflamación específica relacionada con los distintos fenotipos, que son los que podrían definir con mayor precisión cuál sería el tratamiento ideal para contrarrestar un mecanismo fisiopatológico específico (4).

No parece suficiente entonces, establecer un manejo basándose únicamente en la gravedad, ya que existen diversos aspectos que surgen desde el propio concepto de que el asma es una enfermedad heterogénea y con diferentes bases moleculares y genéticas, por lo que encasillar a un paciente dentro de un parámetro general, puede reducir también sus opciones terapéuticas (5).

Por otro lado, el control del asma grave supone un reto para los especialistas en Alergología y Neumología por el alto impacto de esta enfermedad en la calidad de vida de los pacientes.

Las guías GINA establecen niveles de control de la enfermedad según la respuesta al tratamiento, así: bien controlada, parcialmente controlada, y no controlada. No obstante, se puede diferir en cuanto a qué cantidad de pacientes catalogados en alguno de los grados, realmente corresponde a otro, teniendo en cuenta que probablemente un asma parcialmente controlada, en realidad es un asma no controlada y esto tiene implicaciones terapéuticas. En la práctica diaria podría decirse que no pueden establecerse términos medios para definir el manejo. Algunos pacientes persisten sin control a pesar de las recomendaciones terapéuticas establecidas, lo cual permite inferir que, al igual que con la gravedad, existen otros aspectos que deben evaluarse desde la fisiopatología de la enfermedad y no solo basándose en el grado de control de ésta. Adicionalmente, la clasificación fundamentada en el control es muy estricta y está pobremente documentada.

\section{¿Es importante abordar el fenotipo?}

Es claro el hecho de que algunas características se pueden identificar en algunos pacientes asmáticos y no en otros; de allí surge el concepto de "fenotipo", el cual se define como la presencia de diferentes características que son producto de la interacción de los genes con el medio ambiente. En el asma, se han utilizado múltiples estrategias para determinar fenotipos, como por ejemplo las relacionados con las características clínicas (gravedad, limitación de flujo aéreo, edad de inicio, etc.); con los desencadenantes (alergia, aspirina, obesidad, etc.); o con características fisiopatológicas (por ej. patrón de inflamación: eosinófilica, neutrofílica). Se acepta que puede existir solapamiento entre ellos y que un mismo paciente puede migrar de manera transitoria o definitiva de un fenotipo a otro. El reto, por tanto, consiste en determinar en cada paciente estas características individuales (3).

Hace varios años, Chung y Adcock (6), publicaron una revisión sobre los grandes avances logrados en la fenotipificación del asma a partir de investigaciones complejas de correlación clínica y mecanismos fisiopatológicos. El primer estudio sistemático de asma severa realizado en Europa por el grupo ENFUMOSA (European Network For Understanding Mechanisms Of Severe Asthma) (7), consolidó el concepto de que el asma tiene una expresión heterogénea y así, el asma grave debe considerarse una forma diferente de la enfermedad, más que simplemente un aumento de los síntomas de ésta.

Trabajos posteriores incluidos dentro del programa de investigación en asma grave (SARP) de los Estados Unidos, junto con los resultados del grupo ENFUMOSA, y posteriormente del BIOAIR (Longitudinal Assessment of Clinical course and BIOmarkers in severe chronic AIRway Disease) (8), han extendido el conocimiento de las expresiones clínicas y han generado nuevas hipótesis acerca de la fisiopatología del asma grave. De esta forma, se han establecido cinco fenotipos:

1. Asma atópica de inicio temprano con disfunción de la vía aérea, inflamación eosinofílica y número elevado de hospitalizaciones. 
2. Asma con inflamación no eosinofílica, obesidad y presente en el sexo femenino.

3. Asma de inicio temprano, con pocos síntomas e inflamación eosinofílica mínima.

4. Asma con inflamación eosinofílica, con pocos síntomas y de instauración tardía.

5. Asma con inflamación neutrofílica.

\section{El asma grave de inicio temprano}

Comprende el $40 \%$ de todos los asmáticos graves. Los pacientes desarrollan la enfermedad en la niñez y cursan con historia de atopia, mayor hiperreactividad bronquial, niveles más elevados de inmunoglobulina E (IgE) total y un recuento de eosinófilos más alto tanto a nivel periférico como en esputo, además de una tendencia a la fibrosis subendotelial y una sobreexpresión del gen de mucina. En términos generales, responden al manejo con corticoides inhalados. La historia familiar sugiere un componente genético; de hecho, en múltiples estudios se han reportado asociaciones entre genes relacionados con la expresión del fenotipo Th2 y múltiples polimorfismos relacionados con mayor gravedad. El patrón Th2 de citocinas, dentro del que se incluyen las interleucinas (IL) 2, 4, 5, 9, y 13, se expresa en la submucosa bronquial de estos pacientes. Estas citoquinas contribuyen a la inflamación alérgica de la vía aérea, generando la activación y el reclutamiento de linfocitos B productores de $\operatorname{IgE}$ específica, mastocitos, basófilos y eosinófilos. La IL13 actúa además como inductor de los genes del regulador 1 de los canales de cloro, la periostina y el inhibidor de la serpin peptidasa.

Recientemente se ha descrito el papel de la linfopoyetina estromal tímica (TSLP) como inductor de la producción de IL 4, 5 y 13 en el inicio de respuesta celular mediada por células con patrón Th2, así como también de IL 25 e IL 33, las cuales se producen como respuesta a la exposición a alérgenos, contaminantes y virus. La IL 33, que es miembro de la familia de citocinas de la IL-1, posee una potente actividad inductora y quimiotáctica de los linfocitos Th2. Los niveles elevados de IL33 y TSLP se han observado en pacientes con asma, especialmente en los casos graves (9).

\section{Fenotipos con y sin eosinofilia}

Es bien conocido que la presencia aumentada de eosinófilos en el esputo inducido y en sangre periférica puede identificar al subgrupo eosinofílico. Los puntos de corte son: al menos 3\% de eosinófilos en el esputo y una eosinofilia periférica mayor de 350 (número absoluto). El fenotipo no eosinófilico se ha definido como el asma con eosinófilos en el esputo inducido menores al 3\% y una infiltración mayor de neutrófilos. Los mecanismos que expliquen la neutrofilia en la vía respiratoria no son muy claros. Se ha planteado que este fenotipo refleja un patrón "no Th2" con todas sus implicaciones moleculares. Además, se asocia a una pobre respuesta al tratamiento con corticoides inhalados (incluso induciendo aún más neutrofilia), sugiriendo un patrón Th1 orquestado por el factor de necrosis tumoral alfa (TNFa), de el cual se asume puede tener un rol importante. Tanto las células Th17 como la colonización bacteriana de la vía aérea secundaria a defectos en la fagocitosis, han sido implicadas como causas de la neutrofilia (10).

La identificación de fenotipos trae como consecuencia un gran número de tratamientos con objetivos específicos, los cuales vienen desarrollándose desde hace algunos años. El reto es unir la fisiopatología con los fenotipos clínicos y utilizar ese conocimiento para descubrir otros fenotipos aun no reconocidos. Ninguno de los fenotipos clínicos establecidos hasta hoy, posee una identificación detallada de su fisiopatología, biomarcadores, elementos genéticos, estabilidad a través del tiempo, ni de la respuesta a un tratamiento específico. Probablemente, todos los factores que influyen en un fenotipo, necesitarán ser incorporados hacia un endotipo, el cual no es otra cosa que el subtipo definido por el mecanismo funcional o fisiopatológico de la enfermedad para un individuo particular.

El soporte de la evidencia respecto a la conformación de fenotipos y endotipos sigue siendo limitado por la falta de estudios longitudinales a gran escala que puedan entrelazar la fisiopatología con los hallazgos clínicos. Sin embargo, existen ya fenotipos que parecen estar claramente definidos en 
cuanto a su base clínica y molecular, y en los cuales la intervención farmacológica con anticuerpos monoclonales, constituye un importante punto de partida en el manejo del asma grave (2).

\section{Anticuerpos monoclonales}

Los anticuerpos monoclonales son glucoproteínas especializadas producidas por las células $\mathrm{B}$ a partir de una célula madre, formando clones idénticos de ésta. Tienen la capacidad de reconocer moléculas específicas, como por ejemplo citoquinas o receptores.

\section{Nomenclatura}

\section{Anticuerpos quiméricos}

Son moléculas artificiales en las cuales las porciones constantes de las cadenas pesada y liviana provienen de una inmunoglobulina humana y las regiones variables VL y VH (región variable de la cadena liviana y pesada respectivamente) se obtienen de un anticuerpo de origen murino. El objetivo con la construcción de un anticuerpo quimérico es reducir la inmunogenicidad para el humano sin afectar la selectividad del anticuerpo por el antígeno. Estas moléculas presentan un $66 \%$ de componente humano y un $33 \%$ de origen murino, de modo que a pesar de ser menos inmunogénicos que los denominados anticuerpos monoclonales de primera generación, aún pueden inducir respuesta inmune contra ellos. Los anticuerpos de este tipo finalizan con el prefijo ximab (por ejemplo: infliximab, rituximab).

\section{Anticuerpos humanizados}

En éstos, el 90\% del anticuerpo es de origen humano, por lo que al ser inyectado en los pacientes no se produce respuesta del sistema inmune. Solo el sitio de unión al antígeno (paratopo) es de origen murino y está formado a partir de la combinación espacial de las asas hipervariables. El resto de la región variable (región denominada $\mathrm{M}$ ) sólo funciona como un andamio cuya única función es servir de soporte estructural al paratopo. De esta manera, los epitopos asociados a las regiones $\mathrm{M}$ múridas, los cuales están presentes en los anticuerpos quiméricos, no se encuentran en los anticuerpos humanizados. Este tipo de anticuerpos finaliza con el prefijo zumab (por ejemplo: omalizumab, trastuzumab).

\section{Anticuerpos humanos}

Prácticamente el $100 \%$ de su estructura es humana. No obstante, mientras que la producción de anticuerpos monoclonales de ratón se lleva a cabo rutinariamente por la tecnología del hibridoma, la producción de anticuerpos monoclonales humanos mediante esta tecnología ha sido difícil, debido a que los hibridomas humanos y las líneas celulares derivadas de mieloma múltiple han sido difíciles de desarrollar y la inmunización in vivo no es factible para muchos antígenos. Sin embargo, varias técnicas hacen posible la generación de anticuerpos monoclonales humanos, como la expresión de fragmentos de inmunoglobulinas, las fracciones variables de cadena única y las cadenas simples de la fracción variable.

Actualmente, la elaboración de anticuerpos monoclonales recombinantes mediante la tecnología de bibliotecas de fagos con genes que codifican las regiones variables de inmunoglobulinas, ha probado ser útil en la investigación básica y en el campo clínico. Este tipo de anticuerpos finaliza con el prefijo mumab o numab (por ejemplo, adalimumab, sekukinumab) (11-13).

El proceso de producción tradicional de anticuerpos monoclonales se esquematiza en la figura 1 .

\section{Desarrollo y producción}

La producción de anticuerpos monoclonales se basa en el método de la fusión de linfocitos B procedentes de un animal inmunizado (por lo general un ratón), con una línea celular inmortal de mieloma y el cultivo de las células en un medio en el que las células normales y tumorales no fusionadas no puedan sobrevivir. Las células fusionadas resultantes que se obtienen se llaman hibridomas y cada hibridoma produce solo una inmunoglobulina, derivada de un linfocito B del animal inmunizado (11). El procedimiento como tal consiste en la fusión 

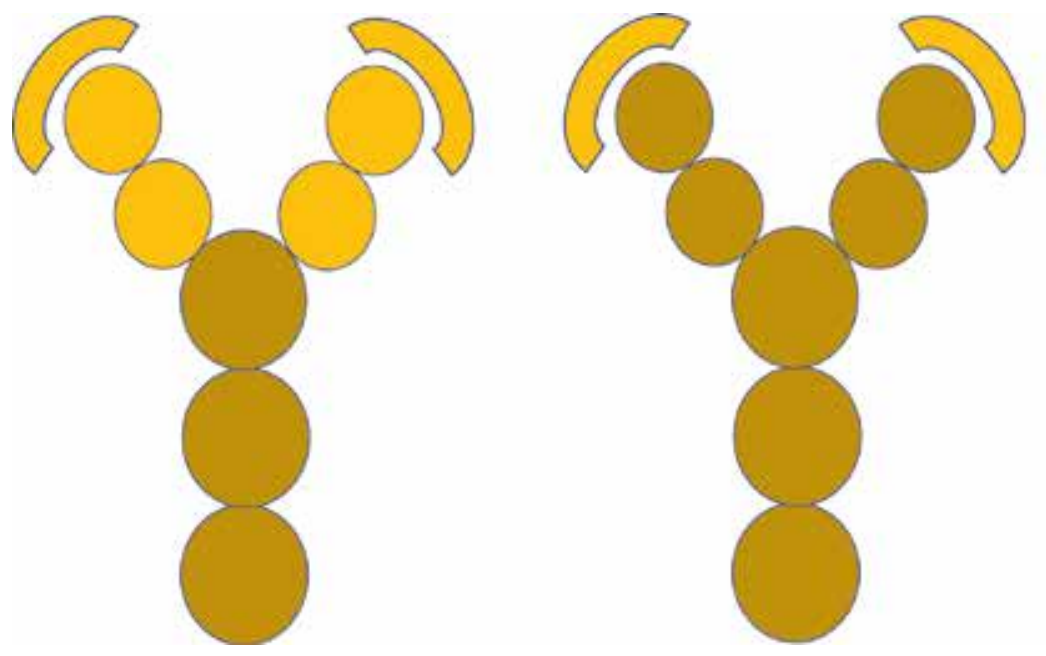

Anticuerpo monoclonal humanizado (> 66\% humano). Sufijo: ZUMAB

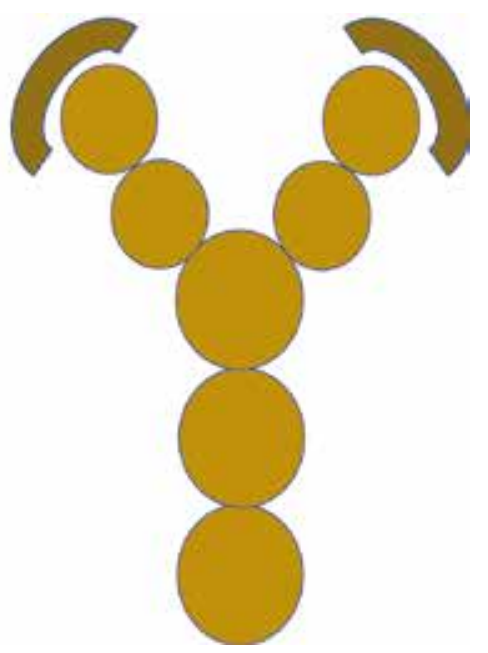

Anticuerpo monoclonal humano (> 99\% humano). Sufijo: MUMAB

Figura 1. Tipos de anticuerpos monoclonales de acuerdo con su humanización.

de células esplénicas de un ratón inmunizado a un antígeno o mezcla de antígenos conocidos, con una línea celular de mieloma, con la subsiguiente formación de células hibridas que conserven muchos cromosomas de las parejas fusionadas. Estas células se colocan después en un medio de selección que permite la supervivencia únicamente de híbridos inmortalizados, los cuales a su vez son cultivados como clones celulares que secretan el anticuerpo de interés. Dicho método de selección incluye hipotaxina, aminopterina y timidina, y por ello se denomina HAT (14). Los hibridomas productores de anticuerpos se expanden en recipientes de cultivo de mayor capacidad y se recogen las células por centrifugación, se suspenden en medio de cultivo suplementado con suero fetal de ternera y dimetil-sulfóxido (DMSO) para congelarlas, primero a $-70^{\circ} \mathrm{C}$ y luego en nitrógeno líquido. La producción del anticuerpo monoclonal se hace a partir del sobrenadante de cultivos en masa o tras la inoculación intraperitoneal del hibridoma en animales histocompatibles. En este último caso se produce un tumor productor de anticuerpos que genera un líquido ascítico rico en éstos. En ambos casos los anticuerpos monoclonales se separan y purifican por los métodos convencionales (15) (figura 2).

\section{Dianas actuales y futuras en el manejo del asma}

\section{Dianas actuales}

\section{Bloqueo inespecífico de la inflamación} (corticoides y antagonistas de leucotrienos)

En la actualidad, el control del asma se centra en el uso de corticoides inhalados, ya sean solos o asociados a antagonistas de leucotrienos, y/o agonistas beta-2 de acción prolongada. Numerosos estudios han documentado la eficacia de los corticoides en la reducción de la inflamación, tanto en niños como en adultos y en cualquier nivel de gravedad. En la actualidad son considerados como los fármacos más efectivos para logar el control en la mayoría de casos. $\mathrm{Su}$ acción requiere la unión a un receptor citoplasmático (GR alfa), el cual está asociado a unas proteínas del choque térmico (Hsp90-Hsp60). La unión del corticoide a su receptor induce la disociación de dichas proteínas y la translocación del complejo hacia el núcleo donde se dan varios eventos que llevan a la activación de la transcripción de genes anti-inflamatorios y al bloqueo de aquellos pro-inflamatorios. Adicionalmente, los corticoides interaccionan directamente con factores de transcripción, tales como el 


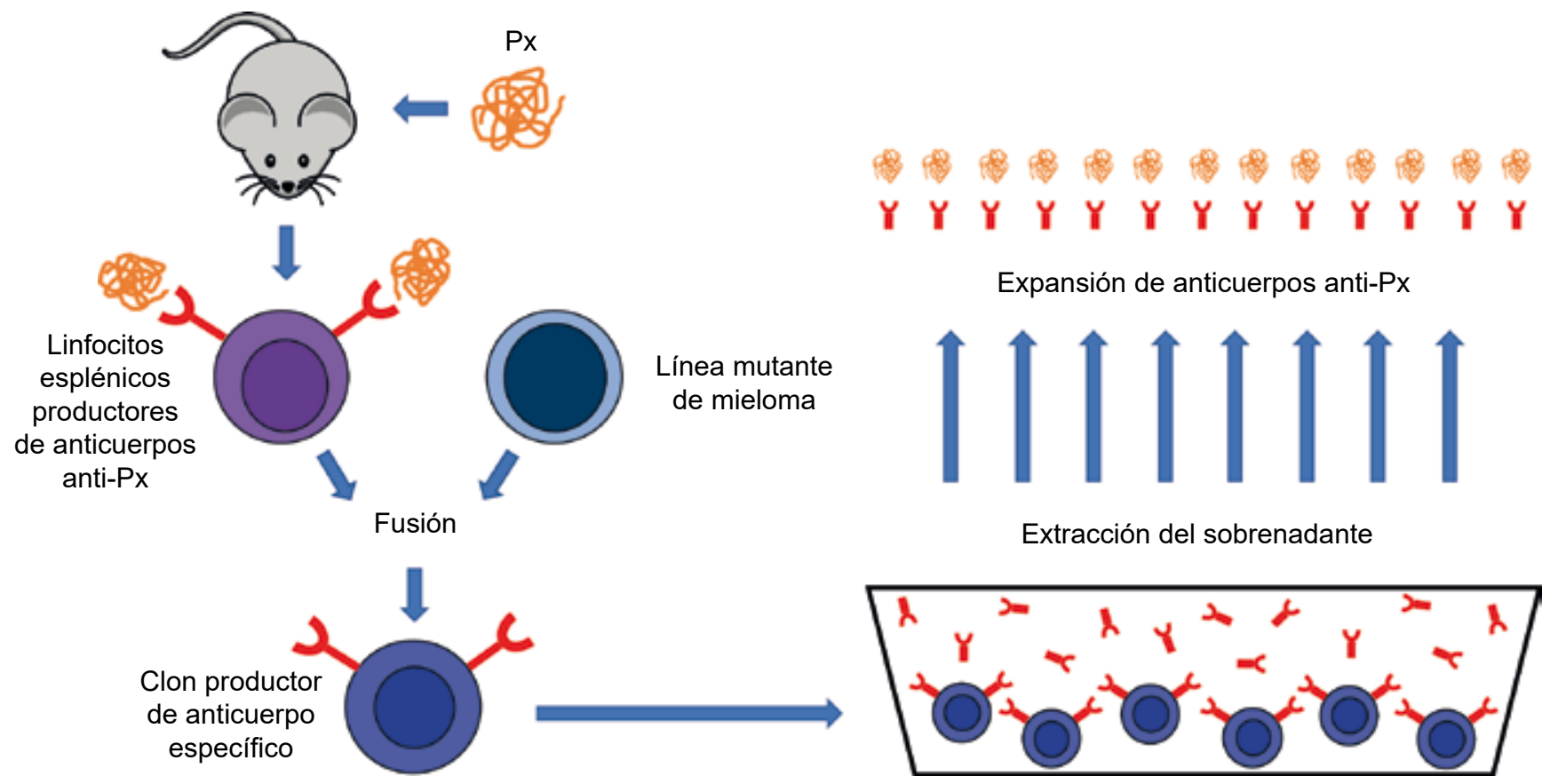

Figura 2. Esquematización del proceso para la producción de anticuerpos monoclonales. Px: proteína " $x$ ".

factor nuclear kappa beta, bloqueando aún más la expansión del proceso inflamatorio.

El empleo de estos fármacos ha permitido conseguir la reducción tanto de los síntomas como de la frecuencia y gravedad de las exacerbaciones, con la consiguiente mejoría de la calidad de vida, lográndose además mejorar la función pulmonar y reducir la hiperreactividad bronquial. No obstante, su falta de especificidad los hace susceptibles a generar efectos adversos en diferentes órganos. Además, existe un porcentaje de pacientes resistentes a los corticoides, fenómeno explicado, entre otras causas, por la presencia de una isoforma de receptor incapaz de unirse al glucocorticoide (16).

Es difícil saber si a mediano o largo plazo, los corticoides continuarán siendo la terapia estándar del asma. Igualmente, resulta incierto saber si el advenimiento de los anticuerpos monoclonales permitirá la reducción de la dosis de corticoides y/o su desmonte total en los pacientes con asma grave.

Los cisteinil leucotrienos comprenden los leucotrienos C4, D4 y E4. Son mediadores que desempeñan un papel importante en la inflamación, la secreción de moco, el broncoespasmo y la remodelación. Los antagonistas de los receptores tipo 1 de los cisteinil leucotrienos (montelukast), son potentes y selectivos, y bloquean su acción de forma competitiva, generando una interrupción de la cascada intracelular pro-inflamatoria con una reducción subsiguiente de sus efectos. Los estudios clínicos demuestran que el antagonismo de estos receptores es beneficioso en cierto grado y porcentaje de la población. Sin embargo, nunca es superior a los efectos que se logran con los corticoides utilizados como monoterapia o en combinación con beta-2 agonistas de acción prolongada. Las indicaciones precisas para su uso en el asma no se hgan definido por completo. Pareciera que su administración en sibilantes precoces tempranos desencadenados por virus y sin atopia, funciona en cierta medida (17).

\section{Broncodilatación con beta 2 agonistas de acción prolongada}

El estímulo agonista de los receptores beta 2 adrenérgicos, genera la relajación del músculo liso de la vía aérea central y periférica, revirtiendo la obstrucción 
bronquial en los asmáticos. El efecto se da por la activación de la adenilato ciclasa (enzima que cataliza la conversión de adenosin trifosfato -ATP- en adenosin monofosfato cíclico -AMPc-), generando el descenso del calcio intracelular, y provocando así la relajación muscular. Este tratamiento, asociado siempre a un corticoide, es de elección cuando no se logra el control con el corticoide inhalado solo (18).

\section{Bloqueo de la inmunoglobulina $E$ (omalizumab)}

La IgE constituye un objetivo terapéutico claro en las enfermedades alérgicas. Una vez es liberada por el plasmocito, la IgE se une a su receptor de alta afinidad en el mastocito y posteriormente, ante la exposición al alérgeno implicado, desencadena varias respuestas efectoras incluyéndose la liberación de mediadores que generan la reacción alérgica. El omalizumab, un anticuerpo monoclonal humanizado recombinante, se une específicamente a la IgE sérica libre en su dominio $\mathrm{CH} 3$, cerca al sitio de unión al receptor de alta afinidad, bloqueando de esta forma su interacción con los mastocitos, basófilos, células presentadoras de antígeno y otras células inflamatorias que expresan el receptor. Dicha unión resulta en la disminución de la IgE libre, generando una retroalimentación negativa del receptor de alta afinidad y, por ende, una interrupción de la cascada inflamatoria evidente por la reducción de los niveles de eosinófilos tisulares y en sangre periférica, así como del GM-CSF, y las IL 2, 4 y 13. También disminuyen la presentación de alérgenos a células $\mathrm{T}$ y la producción de citocinas que estimulan la diferenciación hacia el fenotipo Th2 (19) (figura 3).

La eficacia de omalizumab y su seguridad como tratamiento en el asma grave se ha probado en varios

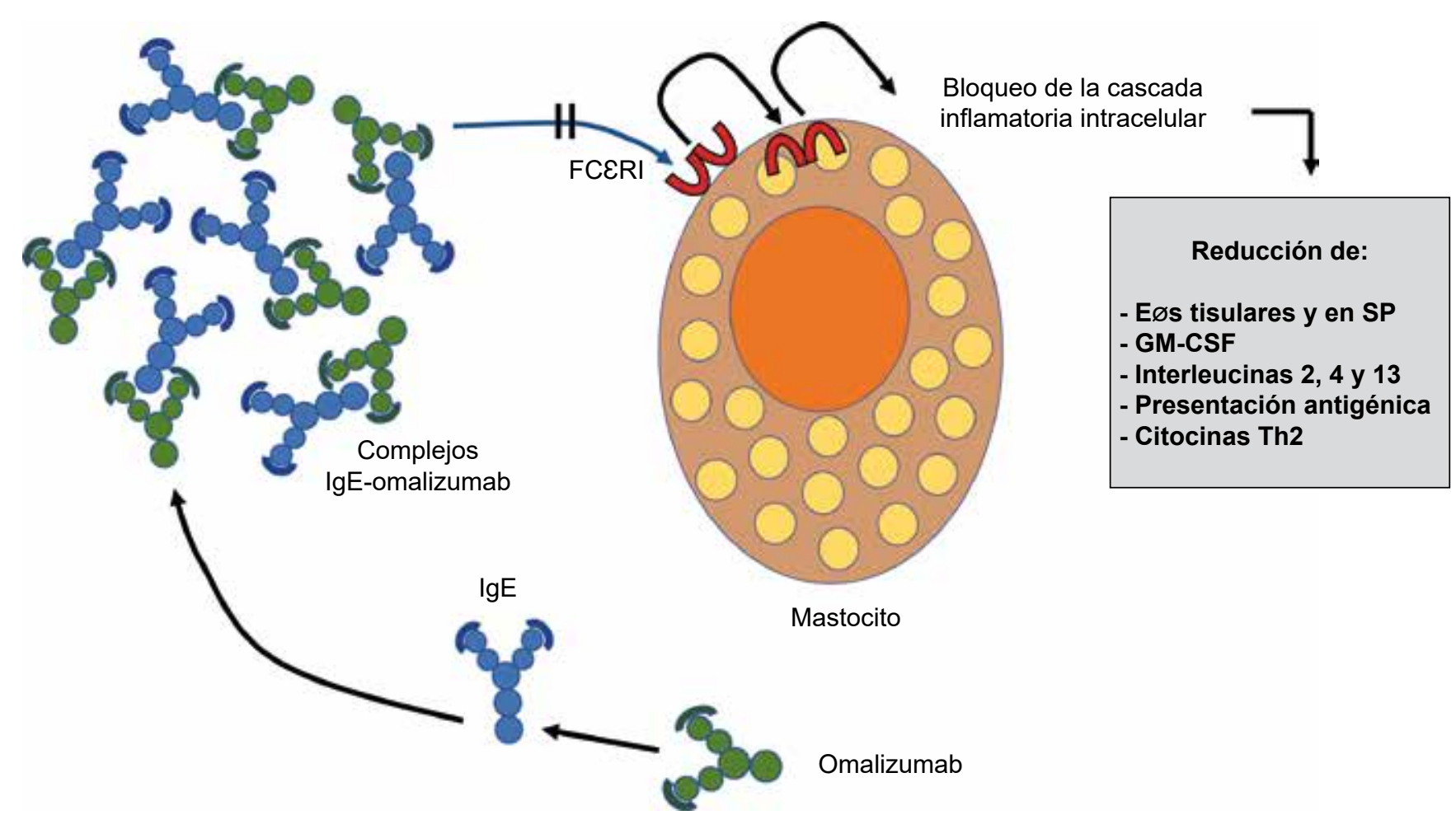

Figura 3. Efectos moleculares del omalizumab. Este anticuerpo se une a la inmunoglobulina $E$ (lgE) soluble, evitando su unión al receptor de alta afinidad en la membrana de los mastocitos. Esto genera una retroalimentación negativa que induce la internalización de dicho receptor y el bloqueo de toda la cascada inflamatoria intracelular con los subsiguientes efectos antiinflamatorios. FCERI: receptor de alta afinidad para la IgE; Eøs: eosinófilos; SP: sangre periférica; GM-CSF: factor estimulante de colonias de granulocitos y monocitos. 
estudios controlados, demostrando una reducción significativa de las exacerbaciones, un efecto ahorrador de corticoides y una mejoría de la calidad de vida. El mayor beneficio se ha observado en los pacientes con asma alérgica, particularmente los de mayor gravedad, que no han respondido al tratamiento convencional (20). Esta sigue siendo su principal indicación desde 2003, año en que fue aprobado por la Administración de Alimentos y Medicamentos (FDA). En 2005, fue aprobado por la Agencia Europea de Medicamentos (EMA) como terapia adicional en pacientes adultos y en niños mayores de 6 años con asma alérgica grave persistente no controlada, con función pulmonar disminuida ( $\mathrm{FEV}_{1}$ menor al $80 \%$ del predicho), a pesar del manejo crónico con dosis altas de corticoides inhalados más agonistas beta 2 de acción prolongada y con evidencia de sensibilización a al menos un aeroalérgeno en la prueba cutánea o mediante determinación de IgE específica en sangre (21). En Colombia, el Invima lo tiene aprobado desde 2005 con la misma indicación.

\section{Dianas futuras}

\section{Citoquinas del subtipo Th2, o con efectos sobre este fenotipo}

\section{Interleucinas 4 y 13}

Son consideradas desde hace mucho tiempo las citoquinas más importantes en la inflamación alérgica en la vía respiratoria; son esenciales para la diferenciación de los linfocitos $\mathrm{CD}^{+}$hacia el fenotipo Th2. Además, son las promotoras del cambio de isotipo hacia la producción de IgE, de la diferenciación del linfocito $\mathrm{B}$ en plasmocito productor de Ig E específica y del reclutamiento de eosinófilos hacia la via áerea a través de los receptores para ellas que se expresan en ellos. También estimulan los mastocitos y otras células proinflamatorias. La IL-13 favorece el desarrollo de fibrosis en la vía aérea y la hipersecreción de moco, y en conjunto con la IL-4, induce la inflamación, el remodelado, y la proliferación de fibroblastos bronquiales y de células musculares lisas (22).

\section{Interleucina 5}

Es producida en su mayoría por las células Th2, mastocitos, basófilos y eosinófilos. Esta citocina condiciona mayoritariamente la población de eosinófilos, desde su diferenciación medular hasta su maduración, supervivencia y activación. Es un inhibidor potente de la apoptosis eosinofílica (23).

\section{Interleucina 9}

Es producida por las células Th2, Th9, basófilos, eosinófilos y mastocitos, y se cree que también por los neutrófilos. Esta citocina actúa uniéndose a su receptor IL-9R alfa, generando un aumento en la proliferación y atracción de los mastocitos. Desempeña un papel muy importante en la diferenciación y la activación de las células Th2. Junto con las interleucinas 4 y 13 actúa en el músculo liso y en el epitelio de la vía aérea contribuyendo a la hiperreactividad bronquial (23).

\section{Factor estimulador de colonias de granulocitos y monocitos (GM-CSF)}

Es un factor de crecimiento implicado en la diferenciación y supervivencia de los eosinófilos (23).

\section{Linfopoyetina estromal tímica (TSLP)}

Es una interleucina 7 epitelial producida como respuesta al estímulo proinflamatorio. Actúa induciendo la liberación de citocinas del patrón Th2. Los pacientes con asma tienen niveles elevados de esta citocina en su vía aérea, mostrando una correlación entre el grado de elevación y la gravedad de la enfermedad. De hecho, varios estudios han evidenciado que algunos polimorfismos en el locus para el gen de la TSLP tienen un efecto protector para el desarrollo de asma e hiperreactividad bronquial (24).

\section{Receptor de la prostaglandina D2}

Es un receptor localizado en las células Th2, las células innatas linfoides tipo 2

(ILC2) y en los eosinófilos. Su ligando natural es la prostaglandina D2. La activación de este receptor, estimula la síntesis de citoquinas Th2. 


\section{Interleucina 25}

Es producida por las células epiteliales como respuesta a diferentes estímulos. Mediante la inducción de GATA 3, favorece la diferenciación hacia células Th2 e ILC2. Tiene un rol esencial en la inflamación de la vía aérea y en el proceso de remodelado (25).

\section{Interleucina 33}

Su origen y acciones son muy similares a los de la interleucina 25. Su efecto es incluso mayor y más potente sobre las células innatas linfoides en comparación con IL-25. Además, activa mastocitos y basófilos y es un factor de supervivencia para eosinófilos (26).

\section{Factor de necrosis tumoral alfa (TNF-a)}

Es producido por células epiteliales, células Th1 y Th17. Favorece el reclutamiento de eosinófilos y neutrófilos hacia la vía aérea mediante la disregulación de las moléculas de adhesión. Activa los macrófagos para la producción de factores de crecimiento y de GM-CSF (25).

\section{Intervención en la vía Th2 con anticuerpos monoclonales}

Las posibles intervenciones terapéuticas con anticuerpos monoclonales que vienen desarrollándose para el tratamiento del asma se esquematizan en la figura 4. Las características de las moléculas principales y la evidencia actual disponible para cada una de ellas, se detallan en la tabla 1 (27-45). Otros anticuerpos monoclonales cuentan con menos estudios y posiblemente tengan un papel residual en el tratamiento del asma (46-51).
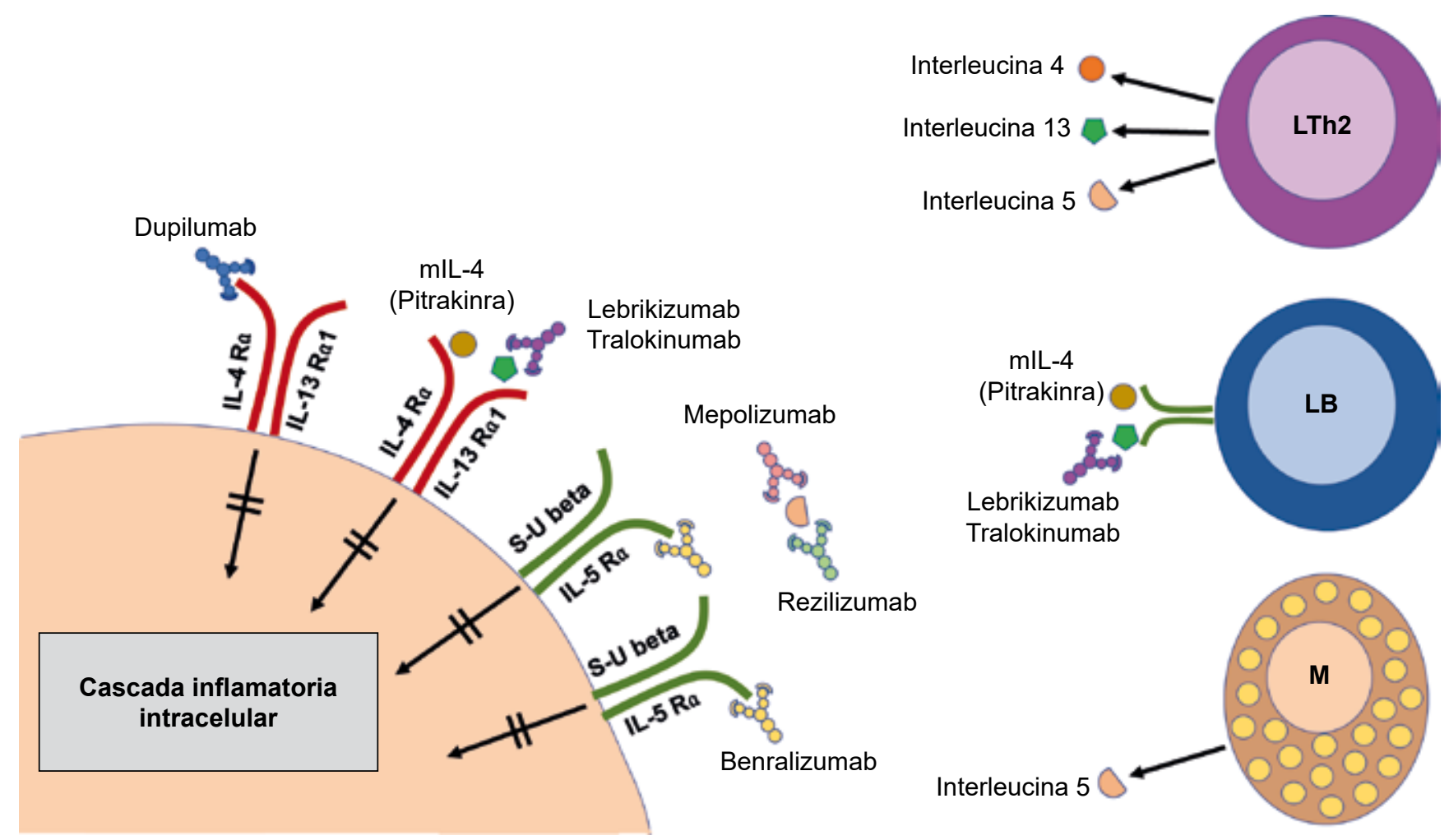

Figura 4. Diferentes anticuerpos monoclonales con sus respectivas dianas terapéuticas dentro de la cascada inflamatoria del asma. La neutralización de los distintos receptores y mediadores, bloquea la cascada intracelular de cinasas que amplifica y propaga el proceso inflamatorio. IL-4Ra: receptor alfa para la interleucina 4; IL-13 Ra1: cadena alfa 1 del receptor de interleucina 13; rIL-4: interleucina 4 recombinante inactiva; S-U: subunidad. 
Tabla 1. Principales anticuerpos monoclonales que se han estudiado para el tratamiento del asma (27-45).

\begin{tabular}{|c|c|c|c|c|c|c|c|}
\hline $\begin{array}{c}\text { Anticuerpo } \\
\text { (Referencias) }\end{array}$ & Tipo & Diana & $\begin{array}{c}\text { Fase de los } \\
\text { estudios }\end{array}$ & Desenlaces clínicos & $\begin{array}{l}\text { Desenlaces } \\
\text { inflamatorios }\end{array}$ & $\begin{array}{l}\text { Dosis/Vía/ } \\
\text { Intervalo }\end{array}$ & $\begin{array}{l}\text { Disponibilidad } \\
\text { en Colombia }\end{array}$ \\
\hline $\begin{array}{l}\text { Benralizumab } \\
(27-31)\end{array}$ & Humanizado & IL-5Ra & II-III & $\begin{array}{l}\text { - Reducción de } \\
\text { exacerbaciones, } \\
\text { incluyendo aquellas } \\
\text { que requirieran } \\
\text { hospitalización } \\
\text { - Mejoría del FEV } \\
\text { - Mejoría de la calidad de } \\
\text { vida }\end{array}$ & $\begin{array}{l}-\downarrow \text { eosinofilia } \\
-\downarrow \text { eosinofilos } \\
\text { en esputo } \\
-\downarrow \text { PCE }\end{array}$ & $\begin{array}{l}20-100 \mathrm{mg} \\
\mathrm{SC} / 4-8 \\
\text { semanas }\end{array}$ & 2019 \\
\hline $\begin{array}{l}\text { Mepolizumab } \\
(32-35)\end{array}$ & Humanizado & IL-5S & II-III & $\begin{array}{l}\text { - Reducción de } \\
\text { exacerbaciones } \\
\text { - Reducción de la dosis } \\
\text { de corticoides orales } \\
\text { (dependientes) } \\
\text { - Mejoría del ACT } \\
\text { - Mejoría del FEV }\end{array}$ & $\begin{array}{l}-\downarrow \text { eosinofilia } \\
-\downarrow \text { eosinofilos } \\
\text { en esputo }\end{array}$ & $\begin{array}{l}75 \text { mg IV / } \\
\text { mes } \\
100 \text { mg } \\
\text { sC / mes }\end{array}$ & 2018 \\
\hline $\begin{array}{l}\text { Resilizumab } \\
(36,37)\end{array}$ & Humanizado & IL-5S & III & $\begin{array}{l}\text { - Mejoría del FEV } \\
\text { - Mejoría del ACT } \\
\text { - Mejoría de síntomas } \\
\text { - Reducción de } \\
\text { exacerbaciones }\end{array}$ & $\begin{array}{l}-\downarrow \text { eosinofilos } \\
\text { en esputo }\end{array}$ & $\begin{array}{l}3 \mathrm{mg} / \mathrm{kg} \\
\mathrm{IV} / \mathrm{mes}\end{array}$ & ND \\
\hline $\begin{array}{l}\text { Dupilumab } \\
(38,39)\end{array}$ & Humano & IL-4Ra & II-III & $\begin{array}{l}\text { - Reducción de } \\
\text { exacerbaciones } \\
\text { - Mejoría del FEV } \\
\text { - Mejoría de la calidad de } \\
\text { vida }\end{array}$ & $\begin{array}{l}-\downarrow \text { de FeNO } \\
-\downarrow \text { lgE total } \\
-\downarrow \text { eotaxina } 1\end{array}$ & $\begin{array}{l}200 \mathrm{mg} \\
\mathrm{SC} / \\
2 \text { semanas }\end{array}$ & 2019 \\
\hline $\begin{array}{l}\text { Pitrakinra } \\
(40,41)\end{array}$ & rlL-4 & IL-4Ra & II & $\begin{array}{l}\text { - Reducción de } \\
\text { exacerbaciones* } \\
\text { - Reducción de } \\
\text { despertares nocturnos* } \\
\text { - Reducción de limitación } \\
\text { de actividades por el } \\
\text { asma* } \\
\text { - Reducción de } \\
\text { exacerbaciones en } \\
\text { pacientes con eosinofilia } \\
\text { - Reducción de la } \\
\text { necesidad de beta-2 de } \\
\text { rescate } \\
\text { - Mejoría FEV }\end{array}$ & $-\downarrow$ de FeNO & $\begin{array}{l}3-10 \mathrm{mg} \\
\text { inhalados / } \\
12 \text { horas }\end{array}$ & ND \\
\hline $\begin{array}{l}\text { Lebrikizumab } \\
(42,43)\end{array}$ & Humanizado & IL-13 & II-III & $\begin{array}{l}\text { - Reducción de } \\
\text { exacerbaciones } \\
\text { - Mejoría del FEV }\end{array}$ & - $\downarrow$ periostina & $\begin{array}{l}125-250 \\
\text { mg SC / } \\
\text { mes }\end{array}$ & ND \\
\hline $\begin{array}{l}\text { Tralokinumab } \\
(44,45)\end{array}$ & Humano & IL-13 & II-III & $\begin{array}{l}\text { - Reducción de la HRB } \\
\text { - Reducción de la } \\
\text { necesidad de beta-2 de } \\
\text { rescate } \\
\text { - Mejoría del FEV }{ }_{1}(\mathrm{NS})\end{array}$ & $-\downarrow$ eosinofilia & $\begin{array}{l}300 \mathrm{mg} \\
\mathrm{SC} / 2-4 \\
\text { semanas }\end{array}$ & ND \\
\hline
\end{tabular}

*Desenlaces asociados a polimorfismos específicos. Otros anticuerpos monoclonales que se han estudiado: anti-TSLP (46); Enokisumab (anti IL-9) (47); anti- GM-CSF (48); anti TNF (49); anti IL-25 (50); anti IL-33 (51).rlL-4: interleucina 4 recombinante inactiva; IL-5Ra: receptor alfa

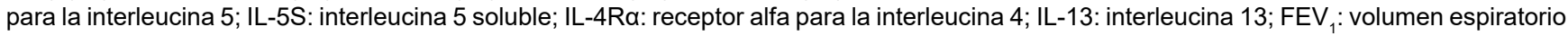
forzado en el primer segundo; NS: diferencia no significativa; ACT: test de control del asma; PCE: proteína catiónica de los eosinófilos; FeNO: fracción espirada de óxido nítrico; IgE: inmunoglobulina E; SC: vía subcutánea; IV: vía intravenosa; ND: dato no disponible. 


\section{Biomarcadores}

Tal como se discutió previamente, la identificación de fenotipos de asma ha tenido un impacto importante en la investigación de biomarcadores que han ayudado a clasificar mejor a los pacientes, a predecir las diferentes posibilidades de evolución de la enfermedad y a monitorizar la respuesta al tratamiento instaurado. El biomarcador ideal debe ayudar a definir la terapia más adecuada, identificar los cambios en la actividad de la enfermedad, ser fácil de realizar y medir, poco invasivo, y muy costo-efectivo. En la actualidad, ninguno de los biomarcadores disponibles cumple con todas estas características. A continuación se describen los más importantes.

\section{Neutrófilos}

En algunos casos de asma grave existe inflamación neutrofílica, la cual se puede presentar concomitantemente con inflamación derivada de la vía Th2, o sin ella. El rol funcional de estas células aún permanece poco claro.

El conteo de neutrófilos en esputo es altamente reproducible en pacientes con asma moderada a grave, y estos pueden considerarse como una posible diana de tratamiento (52). El reclutamiento de estas células está mediado por las células Th17, las cuales se cree que cumplen un rol importante en la patogénesis de la enfermedad, en especial en aquellos pacientes que no responden a los corticoides inhalados. El receptor para productos finales de glucosilación avanzada (RAGE) es un receptor de patrón de reconocimiento involucrado en la respuesta a lesión tisular, infección e inflamación. El estímulo de RAGE y de sus formas solubles parece estar influenciado o relacionado con la inflamación neutrofílica pulmonar. Las formas solubles parecen ser degradadas por enzimas proteolíticas derivadas de los neutrófilos en los pacientes con neutrofilia marcada en la vía aérea y podrían ser un potencial biomarcador pronóstico en estos pacientes (53).

Por otro lado, la metaloproteinasa 8 (ADAM 8) es una endopeptidasa que parece estar involucrada en facilitar la migración de los neutrófilos a los tejidos. Se ha descrito el aumento de esta en las biopsias bronquiales de pacientes con asma grave (54).

\section{Eosinófilos}

Un porcentaje importante de los casos de asma se caracteriza por un reclutamiento de eosinófilos hacia la vía aérea. Su recuento se correlaciona directamente con la gravedad de los síntomas y los episodios de asma con riesgo vital, e inversamente con la función pulmonar (55).

La presencia de eosinófilos está relacionada con un aumento en la expresión del factor trasformador de crecimiento beta (TGF- $\beta$ ) y el grosor de la membrana basal. El reclutamiento está determinado por proteínas secretadas por el epitelio, de las cuales, la de actividad quimiotáctica más potente es la eotaxina-1 (CCL11). Un trabajo reciente evaluó los niveles de esta quemocina en el lavado broncoalveolar, en esputo inducido y en la sangre de pacientes asmáticos, evidenciando una correlación entre su presencia en el esputo y la gravedad del asma. También se ha postulado que la eotaxina-1 podría estar asociada con el aumento en la expresión del factor transformador de crecimiento beta (TGF- $\beta$ ) descrito anteriormente. Incluso se ha demostrado la presencia de TGF- $\beta 1$ en eosinófilos de biopsias bronquiales. La isoforma TGF- $\beta 2$ se expresa en eosinófilos de pacientes con asma alérgica grave, en los cuales esta citocina promueve la inducción de fibrosis y regula la producción de mucina (56).

El recuento de eosinófilos en esputo viene utilizándose hace mucho tiempo para evaluar la inflamación eosinófilica pulmonar y ha mostrado ser un biomarcador confiable y útil para el ajuste de dosis de corticoides (57). Determinando los eosinófilos en esputo se logra identificar el fenotipo de asma grave eosinofílica y de esta forma se puede escoger la terapia a la cual posiblemente habrá una respuesta adecuada (58).

Recientemente, el estudio DREAM (59) correlacionó la dosis efectiva y segura de mepolizumab, con el recuento de eosinófilos en sangre, mas no con el conteo en esputo. Estos datos son avalados por muchos autores quienes han descrito que los eosinófilos en esputo no predicen la respuesta al tratamiento, mientras que un conteo elevado en 
sangre está asociado con mayor riesgo de exacerbaciones, posiblemente explicado por los niveles elevados de interleucina 5 (60).

Otro estudio clave, el EXTRA (61), mostró que la eficacia de omalizumab estaba fuertemente relacionada con la presencia de inflamación eosinofílica de la vía aérea y que existía mayor predicción de respuesta utilizando métodos como el óxido nítrico exhalado (FeNO) y/o los niveles de periostina séricos, en comparación con los niveles de IgE total.

Todo permite deducir que la eosinofilia en sangre como biomarcador podría ayudar a personalizar el manejo del asma alérgica grave. La elección de muchos de los anticuerpos monoclonales que estarán disponibles en el futuro, podría hacerse con base en este biomarcador, al igual que el seguimiento del tratamiento.

\section{Fracción espirada de óxido nítrico (FeNO)}

La sintetasa epitelial inducible de óxido nítrico es el determinante de los niveles de FeNO en el tracto respiratorio. Esta enzima genera un incremento en la producción de óxido nítrico por parte de las células epiteliales bronquiales en respuesta a estímulos proinflamatorios. El tratamiento con corticoides inhalados reduce la FeNO por un efecto inhibitorio sobre la actividad de esta enzima.

La determinación de la FeNO es un método cuantitativo, no invasivo, simple y seguro, que permite evaluar la inflamación de la vía aérea, monitorizar la respuesta a corticoides y establecer el grado de control del asma (62). De hecho, varios estudios han determinado que los niveles de FeNO se correlacionan más con el grado de control de asma que con su gravedad. Recientemente se realizó un trabajo en 416 pacientes asmáticos en tratamiento combinado (corticoides + beta 2 de acción prolongada), y no se halló correlación entre los niveles de FeNO y la gravedad del asma, pero sí entre éste y variables como la edad, el género, la presencia de obesidad, atopia y el número de consultas a urgencias (63).

Las últimas investigaciones resaltan que niveles bajos de la FeNO indican de una respuesta
antiIL-13 e IL-4, lo que sugiere que podría utilizarse como biomarcador en el manejo con anticuerpos monoclonales dirigidos contra estas citoquinas (tralokinumab, pitrakinra y lebrikizumab) (64).

En conclusión, un valor elevado de la FeNO es considerado como un marcador de inflamación Th2 y alergia.

\section{Periostina}

Es una proteína que cumple un papel significativo en la amplificación de la respuesta inflamatoria y su cronificación en las enfermedades alérgicas. Tiene la capacidad de unir moléculas como la fibronectina, la tenascina-C y los colágenos I, III y V. También está implicada en el desarrollo del proceso de fibrosis subepitelial en los asmáticos. Además, tiene la propiedad de unir integrinas a las membranas celulares, activando diferentes vías de señalización. La periostina es inducida por las interleucinas 4 y 13 en la célula epitelial bronquial y en los fibroblastos pulmonares, y su expresión está correlacionada con el grosor de la membrana basal. Tiene también la capacidad de acelerar la infiltración eosinofílica, facilitando su adhesión a la matriz extracelular (65). En este sentido, la periostina puede considerarse un biomarcador sistémico del paciente asmático con patrón inflamatorio Th2. $\mathrm{Su}$ medición es prometedora porque es una proteína que migra con facilidad desde el tejido inflamado hacia la circulación sistémica, lo cual sugiere que sus niveles son un reflejo fidedigno de la presencia de inflamación tisular.

En el estudio BOBCAT (bronchoscopy Exploratory Research Study of Biomarkers in Corticosteroid refractory Asthma) (66), se encontró que la periostina es un muy buen marcador de eosinofilia en sangre periférica y en la vía aérea de pacientes con asma grave. Se adoptó la concentración de 25 $\mathrm{ng} / \mathrm{ml}$ como punto de corte para diferenciar asma asociada y no asociada a eosinofilia, con un valor predictivo positivo del 93\%. El estudio además encontró superioridad de este marcador para predecir eosinofilia tisular y en esputo, respecto a la eosinofilia en sangre periférica, los niveles de FeNO, la IgE total y la proteína plasmática YKL-40. 


\section{Condensado de aire exhalado (CAE)}

El CAE es un líquido que se obtiene a partir de la respiración oral en un condensador hasta un volumen total de 200 litros. La muestra obtenida tras la condensación es alrededor de 2.6 mililitros, los cuáles son representativos en su composición, del líquido que recubre la vía aérea. En el CAE pueden analizarse diversos mediadores, entre los cuales destacan: lipoxinas, leucotrienos, adenosina, peróxido de hidrógeno, marcadores del estrés oxidativo, amonio, citocinas, óxido de nitrógeno y metabolitos del ácido araquidónico (67).

\section{Conclusiones}

Un porcentaje importante de pacientes con asma grave no logra el control de la enfermedad a pesar de recibir tratamiento adecuado. Las guías actuales son obsoletas y lo serán cada vez más si no se incluyen biomarcadores que determinen cuál es el fenotipo predominante en un paciente dado, y qué diana molecular podría ser susceptible de una intervención que represente un beneficio en el control de la enfermedad.

Hasta hoy, omalizumab es el único tratamiento biológico disponible para el manejo de estos pacientes y ha influenciado el inicio de múltiples estudios que avalúan en la actualidad moléculas nuevas y posibles dianas futuras en pacientes seleccionados. Enlazar las características de la enfermedad de cada paciente, con los efectos de un anticuerpo monoclonal determinado, seguramente implicará un control de la enfermedad mucho más efectivo y puntual.

El abordaje detallado de las características fenotípicas y su base molecular, debe conducir a un tratamiento personalizado de gran precisión y efectividad. Una nueva era en el tratamiento del asma se acerca, hecho que resulta muy prometedor.

\section{Bibliografía}

1. Bagnasco D, Ferrando M, Bernardi S, Passalacqua G, Canonica GW. The path to personalized medicine in asthma. Expert Rev Respir Med. 2016; 10:957-65.

2. Wensel S. Severe asthma: from characteristics to phenotypes to endotypes. Clin Exp Allergy. 2012;42:650-8.
3. Dahlen SE. Asthma phenotyping: noninvasive biomarkers suitable for bedside science are the next step to implement precision medicine. J Intern Med. 2016;279:205-7.

4. Boluyt N, Rottier BL, de Jongste JC, Riemsma R, Vrijlandt EJ, Brand PL. Assessment of controversial pediatric asthma management options using GRADE. Pediatrics. 2012;130:65868.

5. Bel EH. Clinical phenotypes of asthma. Curr Opin Pulm Med. 2004;10:44-50.

6. Chung F, Adcock I. Asthma: application of cell and molecular biology techniques to unravel causes and pathophysiological mechanisms. Methods Mol Med. 2000;44:1-29.

7. Abraham B, Anto JME, Barreiro E, Bel EHD, Bonsignore G, Bousquet J, et al. The ENFUMOSA cross-sectional European multicentre study of the clinical phenotype of chronic severe asthma. Eur Respir J. 2003;22:470-7.

8. Kupczyk M, Dahlén B, Sterk PJ, Nizankowska-Mogilnicka E, Papi A, Bel EH, et al. Stability of phenotypes defined by physiological variables and biomarkers in adults with asthma. Allergy. 2014;69:1198-204.

9. Woodruff PG, Modrek B, Choy DF, Jia G, Abbas AR, Ellwanger $\mathrm{A}$, et al. $\mathrm{T}$ helper type 2- driven inflammation defines major subphenotypes of asthma. Am J Respir Crit Care Med. 2009;180:388-95.

10. Zhang Q, Illing R, Hui CK, Downey K, Carr D, Stearn M, et al. Bacteria in sputum of stable severe asthma and increased airway wall thickness. Respir Res. 2012;18:13-35.

11. Almagro JC, Fransson J. Humanization of antibodies. Front Biosci. 2008;13:1619-33.

12. Ballow M. -ximab this and -zumab that! Has the magic bullet arrived in the new millennium of medicine and science? J Allergy Clin Immunol. 2005;116:738-43.

13. Reichert JM, Rosensweig CJ, Faden LB, Dewitz MC. Monoclonal antibody successes in the clinic. Nat Biotechnol. 2005;23:1073-8.

14. Abbas A, Lichtman A. cellular and molecular immunology. 8th. edition. Elsevier; 2015. p. 94-98.

15. Yamada T. Therapeutic monoclonal antibodies. Keio J Med. 2011;60:37-46.

16. Torrego A, Pujols L, Picado C. Response to glucocorticoid treatment in asthma. The role of alpha and beta isoforms of the glucocorticoid receptor. Arch Bronconeumol. 2002;38:43640.

17. Peters-Golden M, Henderson WR. Leukotrienes. N Engl J Med. 2007;357:1841-54.

18. Barnes PJ. Scientific rationale for inhaled combination therapy with long-acting beta2-agonist and corticosteroids. Eur Respir J. 2002;19:182-91.

19. Normansell R, Walker S, Milan SJ, Walters EH, Nair P. Omalizumab for atsthma in adults and children. Cochrane Database Syst Rev. 2014;139:28-35. 
20. Kopp MV. Omalizumab: Anti-IgE therapy in allergy. Curr Allergy Asthma Rep. 2011;11:101-6.

21. Humbert M, Beasley R, Ayres J, Slavin R, Hebert J, Bousquet $\mathrm{J}$, et al. Benefits of omalizumab as add-on therapy in patients with severe persistent asthma who are inadequately controlled despite best available therapy (GINA 2002 step 4 treatment): INNOVATE. Allergy. 2005;60:309-16.

22. Wills-Karp M. Interleukin 13 in asthma pathogenesis. Immunol Rev. 2004;202:175-90.

23. Sokol CL, Barton GM, Farr AG, Medzhitov R. A mechanism for the initiation of allergen-induced $\mathrm{T}$ helper type 2 responses. Nat Immunol. 2008;9:310-8. 24. Brusselle GG, Maes T, Bracke KR. Eosinophils in the spotlight: Eosinophilic airway inflammation in nonallergic asthma. Nat Med. 2013;19:977-9.

25. Boyman O, Kaegi C, Akdis M, Bavbek S, Bossios A, Chatzipetrou A, et al. EAACI IG Biologicals task force paper on the use of biologic agents in allergic disorders. Allergy. 2015;70:727-54

26. Oboki K, Nakae S, Matsumoto K, Saito H. IL-33 and Airway Inflammation. Allergy Asthma Immunol Res. 2011;3(2):81-8.

27. Laviolette M, Gossage DL, Katial R, Leigh R, Olivenstein R, Katial R, et al. Effects of benralizumab on airway eosinophils in asthmatic patients with sputum eosinophilia. J Allergy Clin Immunol. 2013;132:1086-96.

28. Busse WW, Katial R, Gossage D, Sari S, Wang B, Kolbeck R, et al. Safety profile, pharmacokinetics, and biologic activity of MEDI-563, an anti-IL-5 receptor alpha antibody, in a phase I study of subjects with mild asthma. J Allergy Clin Immunol. 2010;125:1237-44.

29. Bleecker ER, FitzGerald JM, Chanez P, Papi A, Weinstein SF, Barker P, et al. Efficacy and safety of benralizumab for patients with severe asthma uncontrolled with high-dosage inhaled corticosteroids and long-acting $\beta 2$-agonists (SIROCCO): a randomised, multicentre, placebo-controlled phase 3 trial. Lancet. 2016;388:2115-27.

30. FitzGerald JM, Bleecker ER, Nair P, Korn S, Ohta K, Lommatzsch $\mathrm{M}$, et al. Benralizumab, an anti-interleukin-5 receptor $\alpha$ monoclonal antibody, as add-on treatment for patients with severe, uncontrolled, eosinophilic asthma (CALIMA): a randomised, double-blind, placebo-controlled phase 3 trial. Lancet. $2016 ; 388 ; 2128-41$

31. Wang FP, Liu T, Lan Z, Li SY, Mao H. Efficacy and Safety of Anti-Interleukin-5 therapy in patients with asthma: a systematic review and meta-analysis. PLoS One. 2016;11:e0166833.32.

32. Nair P, Pizzichini MM, Kjarsgaard M, Inman MD, Efthimiadis A, Pizzichini E, et al. Mepolizumab for prednisonedependent asthma with sputum eosinophilia. N Engl J Med. 2009;360:985-93.

33. Flood-Page P, Swenson C, Faiferman I, Matthews J, Williams $\mathrm{M}$, Brannick L, et al. A study to evaluate safety and efficacy of mepolizumab in patients with moderate persistent asthma. Am J Respir Crit Care Med. 2007;176:1062-71.

34. Haldar P, Brightling CE, Hargadon B, Gupta S, Monteiro W,
Sousa A, et al. Mepolizumab and exacerbations of refractory eosinophilic asthma. N Engl J Med. 2009;360:973-84.

35. Ortega HG, Liu MC, Pavord ID, Brusselle GG, FitzGerald JM, Chetta A, et al. Mepolizumab treatment in patients with severe eosinophilic asthma. N Engl J Med. 2014;371:1198207.

36. Brusselle G, Germinaro M, Weiss S, Zangrilli J. Reslizumab in patients with inadequately controlled late-onset asthma and elevated blood eosinophils. Pulm Pharmacol Ther. 2017;pii:S1094-5539(17)30035-4.

37. Li J, Lin C, Du J, Xiao B, Du C, Sun J, et al. The efficacy and safety of Reslizumab for inadequately controlled asthma with elevated blood eosinophil counts: a systematic review and meta-analysis. J Asthma. 2016. In press.

38. Wensel S, Ford L, Pearlman D, Spector S, Sher L, Skobieranda $\mathrm{F}$, et al. Dupilumab in persistent asthma with elevated eosionophil levels. N Engl J Med. 2013;368:2455-66.

39. Wenzel S, Castro M, Corren J, Maspero J, Wang L, Zhang B, et al. Dupilumab efficacy and safety in adults with uncontrolled persistent asthma despite use of medium-to-high-dose inhaled corticosteroids plus a long-acting $\beta 2$ agonist: a randomised double-blind placebo-controlled pivotal phase $2 \mathrm{~b}$ doseranging trial. Lancet. 2016;388:31-44.

40. Wenzel S, Wilbraham D, Fuller R, Getz EB, Longphre M. Effect of an interleukin-4 variant on late phase asthmatic response to allergen challenge in asthmatic patients: results of two phase 2a studies. Lancet. 2007;370:1422-31.

41. Slager RE, Otulana BA, Hawkins GA, Yen YP, Peters SP, Wenzel SE, et al. IL-4 receptor polymorphisms predict reduction in asthma exacerbations during response to an anti-IL-4 receptor $\alpha$ antagonist. J Allergy Clin Immunol. 2012;130:51622.

42. Corren J, Lemanske RF, Hanania NA, Korenblat PE, Parsey MV, Arron JR, et al. Lebrikizumab treatment in adults with asthma. N Engl J Med. 2011;365:1088-98.

43. Hanania NA, Noonan M, Corren J, Korenblat P, Zheng Y, Fischer SK, et al. Lebrikizumab in moderate-to-severe asthma: pooled data from two randomised placebo-controlled studies. Thorax. 2015;70:748-56.

44. Piper E, Brightling C, Niven R, Oh C, Faggioni R, Poon K, et al. A phase II placebo-controlled study of tralokinumab in moderate-to-severe asthma. Eur Respir J. 2013;41:330-8.

45. Brightling CE, Chanez P, Leigh R, O'Byrne PM, Korn S, She D, et al. Efficacy and safety of tralokinumab in patients with severe uncontrolled asthma: a randomised, doubleblind, placebo-controlled, phase $2 \mathrm{~b}$ trial. Lancet Respir Med. 2015;3:692-701.

46. Gauvreau GM, O’Byrne PM, Boulet LP, Wang Y, Cockcroft D, Bigler J, et al. Effects of an anti-TSLP antibody on allergen induced asthmatic response. N Engl J Med. 2014;370:210210 .

47. Parker JM, Oh CK, LaForce C, Miller SD, Pearlman DS, Le $\mathrm{C}$, et al. safety profile and clinical activity of multiple sub- 
cutaneous doses of MEDI-58, a humanized anti-interleukin-9 monoclonal antibody, in two randomized phase 2 a studies in subjects with asthma. BMC Pulm Med. 2011:11-14.

48. Krinner EM, Raum T, Petsch S, Bruckmaier S, Schuster I, Petersen L, et al. A human monoclonal IgG1 potently neutralizing the proinflammatory cytoquine GM-CSF. Mol Immunol. 2007;44:916-25.

49. Erin EM, Leaker BR, Nicholson GC, Tan AJ, Green LM, Neighbour $\mathrm{H}$, et al. The effects of a monoclonal antibody directed against tumor necrosis factor alpha in asthma. Am J Respir Crit Care Med. 2006;174:753-62.

50. Ballantyne SJ, Barlow JL, Jolin HE, Nath P, Williams AS, Chung KF, et al. Blocking IL-25 prevents airway hyperresponsiveness in allergic asthma. J Allergy Clin Immunol. 2007; 120:1324-31.

51. Liu X, Li M, Wu Y, Zhou Y, Zeng L, Huang T, et al. Anti IL-33 antibody treatment inhibits airway inflammation in a murine model of allergic asthma. Biochem Biophys Res Commun. 2009;386:181-5.

52. Jatakanon A, Uasuf C, Maziak W, Lim S, Chung KF, Barnes PJ. Neutrophilic inflammation in severe persistent asthma. Am J Respir Crit Care Med. 2000;160:1532-9.

53. Barnes PJ, Adcock IM. Glucocorticoid resistance in inflammatory diseases. Lancet. 2009;373:1905-17.

54. Oreo KM, Gibson PG, Simpson JL, Wood LG, McDonald VM, Baines KJ. Sputum ADAM-8 expression in increased in severe asthma and COPD. Clin Exp Allergy. 2013;44:342-52.

55. Hilvering B, Pavord ID. What goes up must come down: biomarkers and novel biologicals in severe asthma. Clin Exp Allergy. 2015;45:1162-69.

56. Al-Alawi M, Hassan T, Chotirmall SH Transforming growth factor $B$ and severe asthma: a perfect storm. Respir Med. 2014;108:1409-23.

57. Wadsworth S, Sin D, Dorscheid D. Clinical update on the use ofbiomarkers of airway inflammation in the management of asthma. J Asthma Allergy. 2011;4:77-86.

58. Newby C, Agbetile J, Hargadon B, Monteiro W, Green R, Pavord I, et al. Lung function decline and variable airway in- flammatory pattern: longitudinal analysis of severe asthma. $\mathbf{J}$ Allergy Clin Immunol. 2014;134:287-94.

59. Pavord ID, Korn S, Howarth P, Bleecker ER, Buhl R, Keene $\mathrm{ON}$, et al. Mepolizumab for severe eosinophilic asthma (DREAM): a multicentre, double-blind, placebo-controlled trial. Lancet. 2012;380:651-9.

60. Malinovschi A, Fonseca JA, Jacinto T, Alving K, Janson C. Exhaled nitric oxide levels and blood eosinophil counts independently associate with wheeze and asthma events in National Health and Nutrition Examination Survey subjects. J Allergy Clin Immunol. 2013;132:821-7.

61. Hanania NA, Wenzel S, Rosén K, Hsieh HJ, Mosesova S, Choy DF, et al. Exploring the effects of omalizumab in allergic asthma: an analysis of biomarkers in the EXTRA study. Am J Respir Crit Care Med. 2013;187:804-11.

62. Yang S, Park J, Lee YK, Kim H, Hahn YS. Association of longitudinal fractional exhaled nitric oxide measurements with asthma control in atopic children. Respir Med. 2015;109:572-9.

63. Gemicioglu B, Musellim B, Dogan I, Guven K. Fractional exhaled nitric oxide (FeNo) in different asthma phenotypes. Allergy Rhinol (Providence). 2014;5:157-61.

64. Sippel JM, Holden WE, Tilles SA, O’Hollaren M, Cook J, Thukkani $\mathrm{N}$ et al Exhaled nitric oxide levels correlate with measures of disease control in asthma. J Allergy Clin Immunol. 2000;106:645-50.

65. Masuoka M, Shiraishi H, Ohta S, Suzuki S, Arima K, Aoki $\mathrm{S}$, et al. Periostin promotes chronic allergic inflammation in response to Th2 cytokines. J Clin Invest. 2012;122:2590600.

66. Jia G, Erickson RW, Choy DF, Mosesova S, Wu LC, Solberg $\mathrm{OD}$, et al. Periostin is a systemic biomarker of eosinophilic airway inflammation in asthmatic patients. J Allergy Clin Immunol. 2012;130:647-54.

67. Serrano CD, Valero A, Bartra J, Roca-Ferrer J, Muñoz-Cano R, Sánchez-López J, et al. Nasal and bronchial inflammation after nasal allergen challenge: assessment using noninvasive methods. J Investig Allergol Clin Immunol. 2012;22:351-6. 